Canadian Journal of Family and Youth, 11(1), 2019, pp. 300-303

ISSN 1718-9748@ University of Alberta

http://ejournals,library,ualberta.ca/index/php/cjfy

\title{
Young, T. (2014). Death by Prescription. Oakville: Mosaic Press.
}

\author{
Reviewed by: Nicole Antunes, MacEwan University
}

Terence H. Young's book, "Death by Prescription", depicts his struggle to overcome losing his fifteen-year-old daughter Vanessa to the multi-billion-dollar world of pharmaceuticals. In an attempt to find the truth behind his daughter's sudden death to the prescription drug, Prepulsid, Young uses his expertise and his power from being a Member of Provincial Parliament in Ontario to uncover and understand drug companies' lack of safety precautions. He seeks to find out why doctors and pharmacists do not take responsibility in disclosing drug side effects and warnings to patients. Young shows a conflict perspective; where the powerful groups, the pharmaceutical companies, dominate smaller groups, such as society. The powerful group is the owner of the means of production; in this case, it would be pharmaceuticals, and they exploit smaller groups for their own personal benefit. Young also uses a first-person narrative in which he shows a strong, negative perspective on the pharmaceutical industry or Big Pharma, as he references. Many of the chapters begin with epigraphs, most of which are stories of young children, who like Vanessa, experienced an adverse drug reaction to a medication because they were not told of the dangers. The chapters are organized in such a way where the reader can follow along right from the death of Vanessa, to Young's careful organization and preparation for his lawsuit against Johnson \& Johnson, and Janssen Pharmaceutical.

Young's relationship with his daughter Vanessa is what causes him to seek out answers to her death. How could doctors, the ones that are supposed to make us feel better and keep us 
safe, do the complete opposite? According to Terrence and his wife, Vanessa was an outgoing, social teenager. She was the empathetic, beautiful teenage that any parent would dream of having. Young recalls a moment where she would leave notes on his desk after a long day of work. Despite these characteristics, Vanessa had one flaw. She had a hard time keeping her food down, which is why she was prescribed Prepulsid. Vanessa's doctors never cautioned her or her family about any safety problems with the drug, such as long QT and heart arrhythmias. The drug was made for stomach problems and bloating but had serious effects on the heart. She had been seeing four doctors since having these issues, and yet the family was never informed of any risk with the prescribed drug.

The main concept that Young uncovers is about safety labels on prescription drugs, as well as doctor's and pharmacist's failure to disclose the dangers of these drugs. He calls Johnson \& Johnson's drug division after the death of his daughter, pleading them to issue a warning about the drug. The division tells him that patients prescribed Prepulsid must have an electrocardiogram, a heart test, before being prescribed anything. This test would have been important in Vanessa's case because "telling doctors to order this test before prescribing Prepulsid would alert them that a stomach drug could adversely affect the heart" (p. 33). "Dear Doctor" letters that outlined the dangers and warnings of the drug were presumably sent out, according to the division, yet the family was never notified of the risks. This indicates that doctors were not reading the safety precautions, and not informing patients about the warnings associated with the medication. During the trial, all four doctors that had been seeing Vanessa as a patient, testified to not reading the letters. Young brings attention to the differences between the safety precautions between the U.S and Canada, and how the U.S issued a "black box warning" on Prepulsid, an important FDA-approved label outlying the risks of adverse drug 
reactions or even death. The drug in Canada was labelled with small print writing and medical jargon that an average consumer may not understand. Because of this, Young says, his daughter's death "was not only preventable, but predictable” (p. 40). It was predictable because the warning was so insignificant that most people would miss it.

Young depicts the corruption of medical professionals and companies that do not follow proper protocols and safety requirements in regards to drugs. He mentions how these drug companies "market their failures" (p. 166) by taking a drug and marketing it for something else, such as the side effect it showed in a different problem. We also learn that the relationship between physicians and pharmaceutical companies has nothing to do with safety, but instead profit. The more prescriptions of a drug they write up, the more profit they receive in return. "Detail representatives" are sent out by drug companies to learn sales techniques; and then they influence doctors to sell whatever drug the companies are trying to promote. These drug representatives influence and bribe doctors with luxury gifts and lavish trips, which creates a win-win situation for doctors and the drug companies, whose sales then increase. As Young puts it, "to a drug company, every disease or condition is a way to sell drugs" (p. 236).

The concept of family is one of the themes in the book. Young describes his family as being one of "many blessings" (p. 21). Despite the devastating loss of his daughter, Young shows us how his family's strength led them to many achievements and milestones. His wife, Gloria, worked for public affairs in the medical system, but later pursued an interest in cooking and received a chef's diploma. Their son, Hart, finished high school with honours, and their daughter succeeded through college. Despite the pressures put on the family throughout Young's preparation of the trial, they stayed strong, and supported him through the process. After the trial, an exposé about Johnson \& Johnson holding back safety information was 
published in a paper. This was important because the story shed light on the problems behind medical institutions, and reach a bigger audience; it would allow others in similar situations to be more cautious. If Young didn't go public about his daughter's death, other patients and other families may have lost someone to the very same thing. After his case, Young became the founder of Drug Safety Canada, which calls for better safety measures in regards to pharmaceuticals and aims to provide the necessary information patients need.

Those who would find "Death by Prescription" informative and important would be anyone in the healthcare or medical profession, teachers, parents and everyday people. This book is necessary and extremely important for those groups specifically because it illustrates the dangers of prescription drugs, and shows the violations that pharmaceutical companies make in order to make profit, despite putting consumers at significant risks. Despite whether or not there are significant changes in the way prescription drugs are promoted and marketed, doctors and medical professionals can learn from the mistakes of those mentioned in the book and take responsibility.

Another audience that would benefit from this book would be members of Parliament or government officials. Young, a member of Parliament, used his determination and his power to help establish Drug Safety Canada. The reason this audience is important is because they are often people who have power and a voice to bring about change, specifically in the pharmaceutical industry and the laws on drug safety. I found "Death by Prescription" to be a very informative and eye-opening read. Before reading this, I had no idea of the corruption and lack of humanity that these multi-billion dollar corporations have; therefore, I would recommend this to anyone who is interested in health, the law, or just needs a shift in perspective in regards to our health and safety regulations. 